\title{
STUDIES ON MECHANICAL AND WEAR BEHAVIOUR OF PARTICULATE REINFORCED MMCS
}

S. Venkat Prasat ${ }^{\# 1}$, M. Hariharavibin ${ }^{\# 2}$, S. Karthick ${ }^{\# 3}$, K. Muni kumar ${ }^{\# 4}$ \#1,2,3,4 Department of Mechanical Engineering, Sri Ramakrishna Engineering College, Coimbatore- 641 022, Tamil Nadu, India.

\section{ABSTRACT}

Use of composites is increasing rapidly in automotive and aerospace applications. In the present industrial scenario, synthesis of Metal Matrix composites (MMCs) with superior wear and mechanical properties is of paramount importance. Researchers have conducted various investigations on MMCs with different reinforcement materials. Hardness test, compression test and wear test were conducted on MMCs with various reinforcement contents and unreinforced Aluminium. The results show an increase in hardness value and compression strength of reinforced MMCs when compared to unreinforced aluminium. The wear rate was also reduced with reinforced MMCs but whereas there was an increase in brittleness. It was also determined that at higher loads, the wear rate of composites increases. The surface roughness of the composites developed decreased with increase in the amount of reinforcement, compacting pressure and sintering temperature.

Key words: Metal Matrix Composites, Aluminium, Reinforcement, Hardness test, Compression Test, Wear test

Corresponding Author: S.Venkat Prasat

\section{INTRODUCTION}

A composite is a material that is formed by combining two or more materials to achieve superior properties when compared to monolithic alloy. Most of the materials which we see around us are composites. Some of them like woods, bones, stones, etc., are natural composites, as they are either grown in nature or developed by natural processes. Some composites are formed by matrix combination depending upon the application.

The matrix is basically a homogeneous and monolithic material in which a fibre system of a composite is embedded. It is completely continuous. The matrix provides a medium for binding and holding reinforcements together into a solid. It offers protection to the reinforcements from environmental damage, serves to transfer load, and provides finish, texture, colour, durability and functionality [1]. There are three types of composite matrix materials. They are ceramic matrix, polymer matrix and metal matrix [2].

Ceramic matrix composites (CMCs) are a subgroup of composite materials. They consist of ceramic fibres embedded in a ceramic matrix, thus forming a ceramic fibre reinforced ceramic (CFRC) material. The matrix and fibres can consist of any ceramic material. CMC materials were designed to overcome the major disadvantages such as low fracture toughness, brittleness, and limited thermal shock resistance, faced by the traditional technical ceramics [2]. 
Polymer matrix composites (PMCs) can be divided into three sub-types, namely, thermoset, thermoplastic, and rubber. Polymer is a large molecule composed of repeating structural units connected by covalent chemical bonds. PMC's consist of a polymer matrix combined with a fibrous reinforcing dispersed phase. They are cheaper with easier fabrication methods. PMC's are less dense than metals or ceramics, can resist atmospheric and other forms of corrosion, and exhibit superior resistance to the conduction of electrical current [2].

Another important type is MMCs which are now widely used in the industries. MMCs are composite materials that contain at least two constituent parts, a metal and another material or a different metal. The metal matrix is reinforced with the other material to improve strength and wear. Where three or more constituent parts are present, it is called a hybrid composite. In structural applications, the matrix is usually composed of a lighter metal such as magnesium, titanium, or aluminium. In high temperature applications, cobalt and cobalt-nickel alloy matrices are common. Typical MMC's manufacturing is basically divided into three types: solid, liquid, and vapour. Continuous carbon, silicon carbide, or ceramic fibres are some of the materials that can be embedded in a metallic matrix material. MMCs are fire resistant, operate in a wide range of temperatures, do not absorb moisture, and possess better electrical and thermal conductivity. They have also found applications to be resistant to radiation damage, and to not suffer from outgassing. Most metals and alloys make good matrices for composite applications [2].

Mostly aluminium based MMCs are used in wide range of applications. Aluminium metal matrix composites are gaining widespread acceptance for automobile, aerospace, agriculture farm machinery and many other industrial applications because of their essential properties such as high strength, low density, good wear resistance compared to any other metal. The present study deals with the addition of reinforcements such as graphite, fly ash, silicon carbide, red mud, organic material etc., to the Aluminium matrix in various proportions. Each reinforced material has an individual property which when added improves the properties of the base alloy. An effort has been made to review the different combinations of the composites of aluminium and how they affect the mechanical properties like hardness and tensile strength. The process shows that MMCs can be replaced with other conventional metals for better performance and longer life [2].

\section{MATERIALS AND EXPERIMENTAL PROCEDURE}

\subsection{Fabrication by Powder Metallurgy}

Al 7075 rod of $25 \mathrm{~mm}$ in diameter was turned in lathe machine and scraps are collected with the ball milling, the scraps are made as the powder. By using the Design Expert software, SiC and $\mathrm{TiC}$ were added according to the matrix along with $\mathrm{Al} 7075$ and the mixture was blended well. The blended powder was poured into the die and compacted in certain pressure (20-25 tonnes) using universal testing machine. The green compact was sintered in the furnace at $75 \%$ of the melting point of $\mathrm{Al} 7075(550 \circ \mathrm{C})$ and then the sample was allowed to cool for 8 hours in the furnace [3].

TiN powder in different weight percentages 5, 10 and 15 were mixed with aluminium using horizontal mill for about 30 minutes. During mixing a control agent was added to avoid agglomeration and cold welding of powder particles. Each of the blended mixtures were pressed at two different compaction pressures of $250 \mathrm{MPa}$ and $300 \mathrm{MPa}$ using uniaxial hydraulic press and lubricated dies. The cold pressed specimens were sintered in nitrogen atmosphere at $4000 \mathrm{C}$ and $4500 \mathrm{C}$ for 4 hours using tube furnace. The density of compacts were measured by volumetric method, where weight and dimensions were measured with the help of an accurate weighing balance $( \pm 0.01 \mathrm{mg})$ and a micro meter $( \pm 0.1 \mathrm{~mm})$ respectively.

Brinell hardness of the samples was measured. Before the compression test, the surfaces of the specimen were polished using an emery paper to have uniform distribution of 
load. Compression test was conducted according to ASTM-D 618. The surface roughness of each specimen was determined using surface roughness tester and an SEM micrograph was used to study the morphology of sintered specimens [5].

\subsection{Fabrication by Stir Casting Process}

Aluminium 6063 in the form of billet is melted in the crucible of the Stir Casting equipment to a temperature of $700^{\circ} \mathrm{c}$ and then the dried alloying metals like Magnesium $(0.5 \%)$ and Zinc $(0.5 \%)$ is added, the percentage of Magnesium and Zinc are kept constant for all the batches. The Graphite $(2 \%, 4 \%, 6 \%)$ and Graphene $(2 \%, 4 \%, 6 \%)$ reinforcement is added respectively to each batch, henceforth three batch of composites with three different percentage of reinforcement were obtained. The total output weight of the stir casting is $1100 \mathrm{~g}$ and the percentages were calculated from that reference weight. The stirrer is made to rotate at an rpm of 300 in order to obtain a uniform dispersion of the reinforcements and 'coverall' is added to remove impurities present in the casting. The final MMC obtained from casting is about $300 \mathrm{~mm}$ in length and $30 \mathrm{~mm}$ in diameter [4].

Aluminium rods 1800 grams, 200 grams of fly ash powder, 200 grams of granulated blast furnace slag are weighed on electronic weighing machine. Then ingots of aluminium are cut into smaller pieces. Now aluminium pieces are put in furnace and heated up to $700^{\circ} \mathrm{C}$. The graphite crucible is preheated on furnace and after pre heating of the crucible aluminium was melted inside the crucible, after the aluminium has reached to molten state the preheated fly ash and blast furnace slag particulates were introduced individually to make the fly ash and blast furnace slag reinforced composites respectively. As the casting is chosen to be stir casting method, the entire liquid inside the crucible was thoroughly stirred with graphite stirrer manually. This molten liquid is prolong heated up to 20 minutes for its morphological transformation. Then the molten metal was poured into permanent mould cavity i.e. a die with dimensions 130x20 millimetre cross-sectional area. The casting is allowed for air cooling [6].

Aluminium silicon alloy and graphite powder were used as matrix alloy and reinforcement phase respectively. $10 \%, 0.10 \%, 0.10 \%, 0.50 \%, 0.60 \%, 0.20 \%$ of $\mathrm{Si}, \mathrm{Mg}, \mathrm{Cu}$, $\mathrm{Mn}, \mathrm{Fe}$, Ti respectively were taken with $\mathrm{Al}$ of remaining portions are the mixture to prepare Al-Si alloy. The composite required for the investigation was fabricated by gravity die stir casting procedure. The final composites were cast to the size of $25 \mathrm{~mm}$ diameter and $250 \mathrm{~mm}$ length. Mineral graphite is one of the allotropes of carbon. Graphite is the most stable form of carbon under standard conditions [7].

To characterize the tribological properties of the prepared composite, the experiments were performed using a computer controlled pin-on-disc tribometer under ambient conditions of room temperature and humidity as per ASTM test standards. EN31 steel disc with the hardness of $60 \mathrm{HRC}$ and ground to surface finish of 1.6 Ra was mounted and secured tight perpendicular to the axis of rotation. The wear test specimens were machined into pins of size $10 \mathrm{~mm}$ diameter, $25 \mathrm{~mm}$ length using a lathe from the cast composite. The end of specimens were polished with abrasive papers of grade $1 / 0$ and followed by grade $4 / 0$. The pins were cleaned with acetone and weighed before and after testing to an accuracy of $\pm 0.0001 \mathrm{~g}$ to calculate the wear value. The sliding end of the pin and the disc surface were cleaned with acetone before testing. The pin specimen was inserted in its holder and adjusted, so that the specimen was perpendicular to the disc surface during contact. Appropriate load from $1 \mathrm{~kg}$ to $4 \mathrm{~kg}$ were added to the system lever to develop the selected force pressing the pin against the disc. The counter balance weights were accustomed, so that the whole cross section of the specimen was mounted with load. The load acting tangentially on the disc and the depth of wear were noted through the electrical display unit, which increases with the application of load. Initially the displacement sensor and the tangential force sensor were adjusted and set to 
zero, which measures the tangential force and the pin displacement. This tangential component was used for calculating the friction component. The signals from sensors after processing in controller were used to investigate the wear mechanisms and characteristics of transfer layer and the pins were analysed using Scanning Electron Microscope [7].

\section{RESULTS AND DISCUSSION}

\subsection{Studies on Hardness Test}

The results of micro hardness test of the samples produced through powder metallurgy of $\mathrm{Al}$ 7075 alloy reinforced with Nano-SiC and NanoTiC. The micro hardness results of the samples are attributed to the fact that pure aluminium 7075 shows lowest micro hardness when compared to other samples reinforced with $\mathrm{SiC}$ and $\mathrm{TiC}$. Incorporation of $\mathrm{TiC}$ alone in the aluminium matrix leads to the higher micro hardness value which is evident in sample 1 which has $100 \%$ of $\mathrm{Al}, 0 \%$ of $\mathrm{SiC}$, and $8 \%$ of $\mathrm{TiC}$. However, addition of $\mathrm{SiC}$ increases the micro hardness value which can be noted in sample 8 which was produced with $100 \%$ of $\mathrm{Al}$, $8 \%$ of $\mathrm{SiC}$, and $8 \%$ of $\mathrm{TiC}[3]$.

Figure 1 shows indentation of the micro hardness test of pure aluminium. Figure 2 shows the indentation of sample 10 which was produced with $100 \%$ of $\mathrm{Al}, 8 \%$ of $\mathrm{SiC}$, and $8 \%$ of TiC. It is evident from these figures that the hardness of the composite material was much higher than that of the pure metal. It was observed that the hardness of the composite material increases with the increase in weight $\%$ of $\mathrm{TiC}$ and $\mathrm{SiC}$ content. The addition of $\mathrm{TiC}$ and $\mathrm{SiC}$ makes the ductile Al 7075 alloy into more brittle in nature. Similarly, the incorporation of $\mathrm{TiC}$ and $\mathrm{SiC}$ in the aluminium matrix enhances the hardness of the samples [3].

The specimens which are manufactured by both powder metallurgy and stir casting is made to undergo static mechanical testing like tensile and compression (all the test specimens are made in accordance with the ASTM standards i.e. dog bone for tensile and cylindrical for compression) [4].

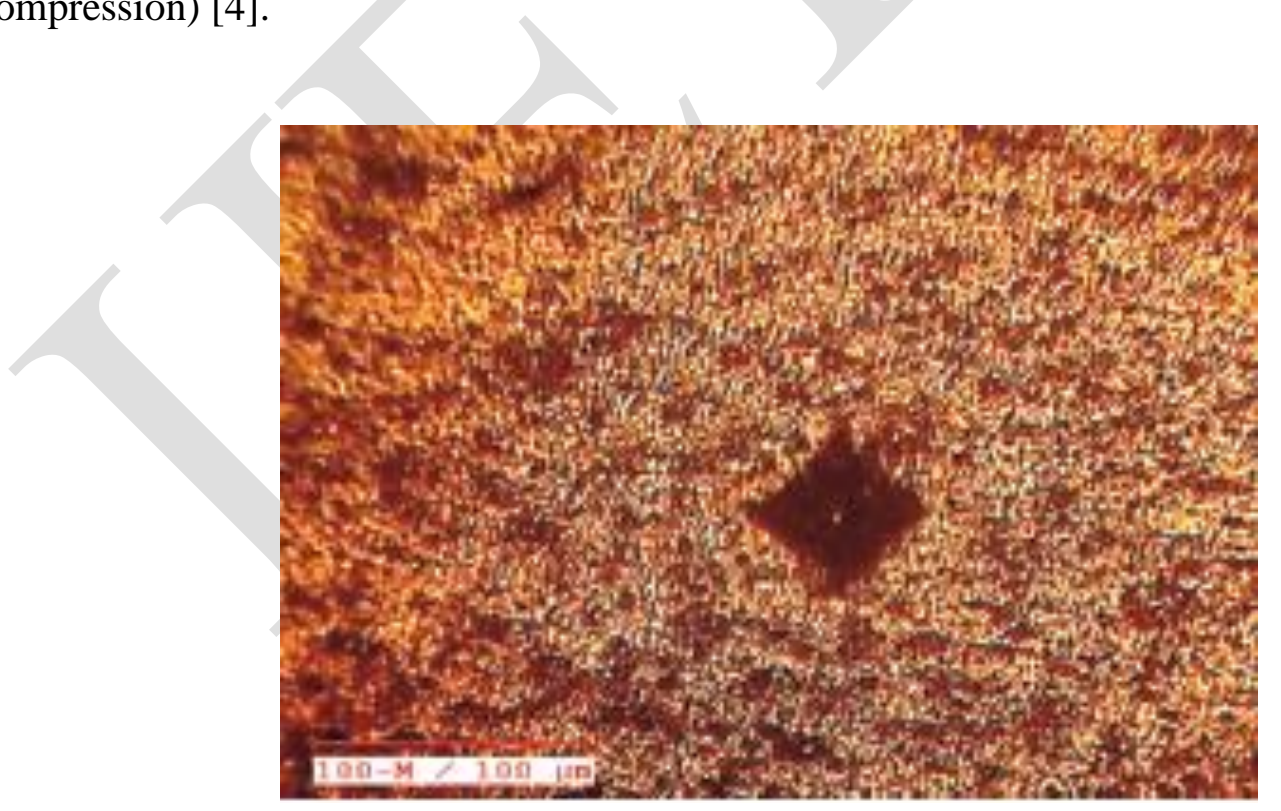

Figure 1: Indentation image of the sample produced with $100 \%$ of Al (Pure aluminium) [3] 


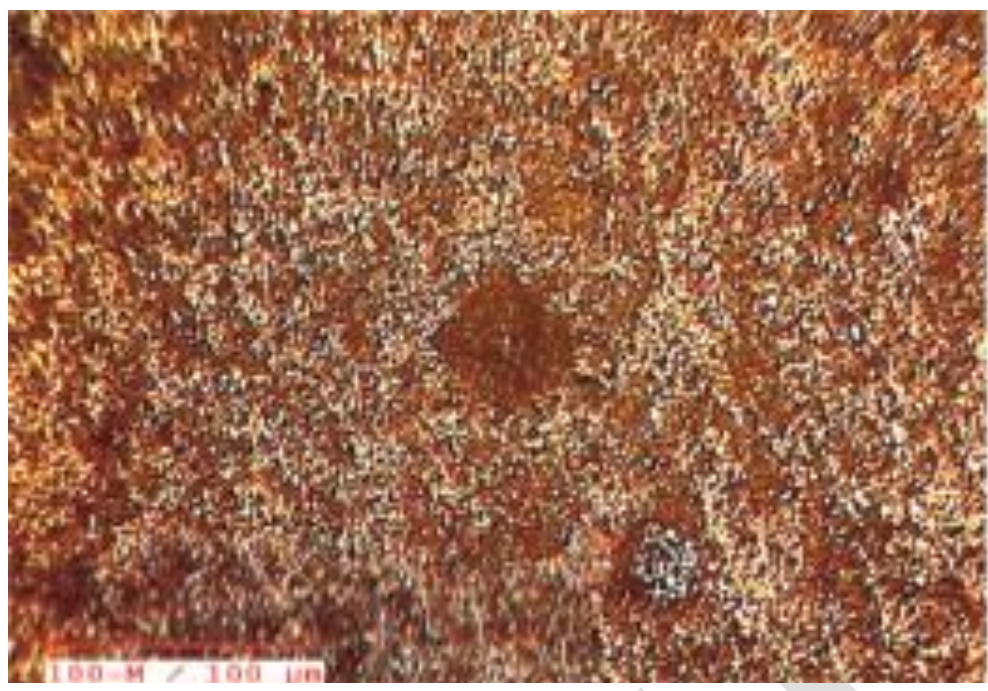

Figure 2: Indentation image of the sample produced with $\mathrm{Al}, 8 \%$ of $\mathrm{SiC}$ and $8 \%$ of $\mathrm{TiC}$

The results obtained from the CES-Edupack and Physical testing were almost in accordance with each other. Vickers Hardness tests were taken for all the specimens whose results are presented below in table 1 and table 2 [4]. Three set compacts were used to determine Brinell hardness number of $\mathrm{Al} \mathrm{TiN} \mathrm{composites} \mathrm{for} \mathrm{each} \mathrm{weight} \mathrm{percentage} \mathrm{of} \mathrm{TiN.}$ Figure 3 shows the variation of hardness of the Al-TiN composites for different weight percentage of TiN [5].

Table 1: Vickers Hardness Test at $0.5 \mathrm{~kg}$ Load, by casting [4]

\begin{tabular}{|c|c|c|c|}
\hline S.No. & Location 1 (HV) & Location 2 (HV) & Location 3 (HV) \\
\hline 1 & 76.0 & 74.9 & 74.7 \\
\hline 2 & 48.3 & 45.9 & 44.3 \\
\hline 3 & 50.1 & 52.5 & 48.1 \\
\hline 4 & 37.5 & 39.4 & 35.5 \\
\hline
\end{tabular}

Table 2: Vickers Hardness Test at 15kg Load, by powder metallurgy [4]

\begin{tabular}{|c|c|c|c|}
\hline S.No. & Location 1 (HV) & Location 2 (HV) & Location 3 (HV) \\
\hline 1 & 58.05 & 58.08 & 58.07 \\
\hline 2 & 131.94 & 131.68 & 132.01 \\
\hline 3 & 118.23 & 118.25 & 118.20 \\
\hline 4 & 100.98 & 100.95 & 100.93 \\
\hline
\end{tabular}

The hardness of composite with $10 \%$ TiN was found to be $17 \%$ higher than the unreinforced aluminium sample. It was observed that Al-TiN composite pressed at $300 \mathrm{MPa}$, followed by sintering at a temperature of $4500^{\circ} \mathrm{Cfor}$ a sintering of 4 hours exhibit higher hardness [5]. 


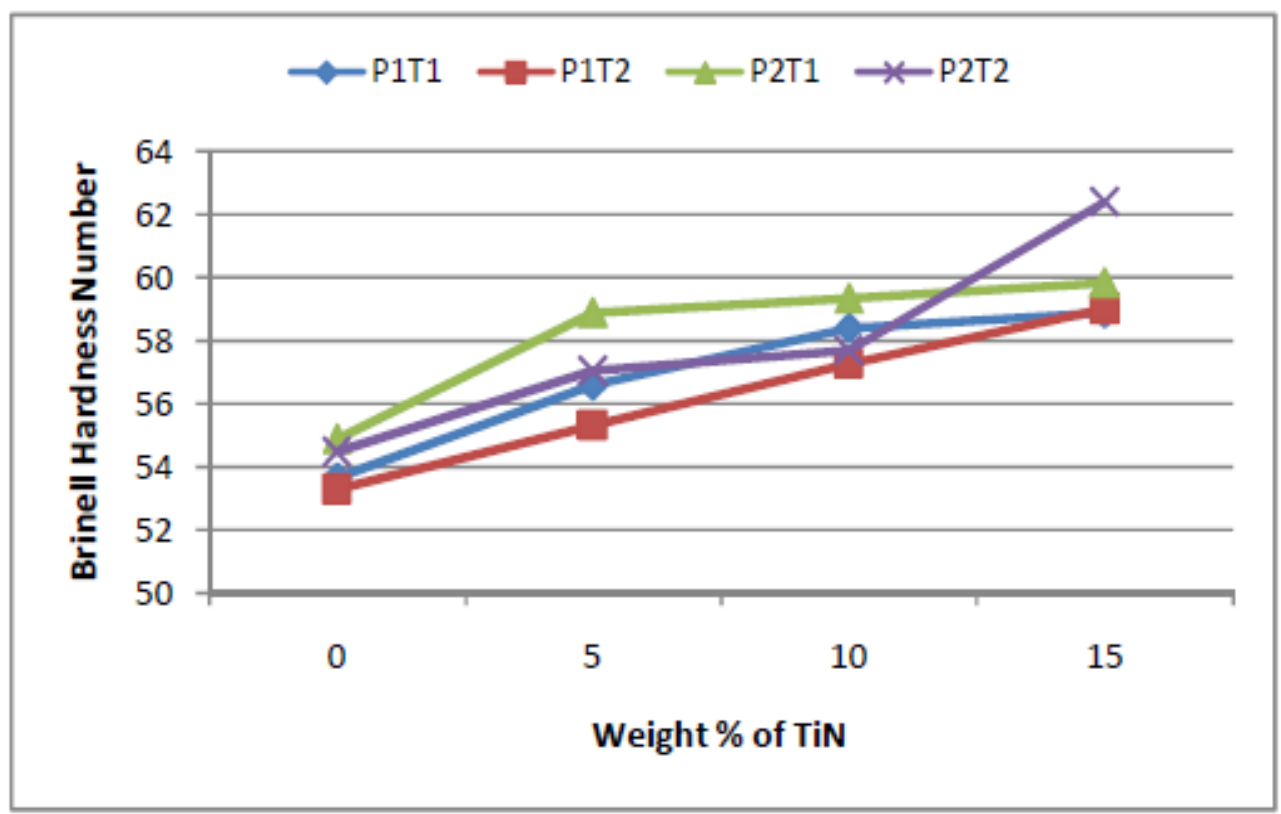

Figure 3: Variation of Hardness for different weight percentages of TiN reinforced Al composites at two different compacting pressure and sintering temperature [5]

The hardness value varies from one place to another place in material because of various factors such as composition difference, type of cooling etc. The average hardness of Al-fly ash has been obtained as for $47.10 \mathrm{HBW}$ and for Al-GBF has been obtained for 44.17 HBW. Hardness obtained from the prepared Al-fly ash is approximately greater than Al-GBF shown in the table $3[6]$.

Table 3: Hardness test results on Brinell scale [6]

\begin{tabular}{|c|c|c|c|c|c|}
\hline S.No. & Material & Trial 1 & Trial 2 & Trial 3 & $\begin{array}{c}\text { Average } \\
\text { Hardness } \\
\text { (BHN) }\end{array}$ \\
\hline 1 & Al-Fly ash & 47.50 & 47.50 & 46.30 & 47.10 \\
\hline 2 & Al-GBF & 43.70 & 45.10 & 43.70 & 44.17 \\
\hline 3 & Al 204 & 25.00 & 24.00 & 24.00 & 24.33 \\
\hline
\end{tabular}

The hardness value of the Al-Si alloy was calculated as per the ASTM standard by using the hardness testing machine. The alloy was mounted on the hardness testing machine and then $100 \mathrm{~kg}$ of force was applied on the specimen material. From the observed values it was found that the hardness of the prepared composite has been increased to 108 and the values are given in the following table 4 [5].

Table 4: Hardness Values of Various Specimens [6]

\begin{tabular}{|c|c|c|}
\hline Specimen & $\begin{array}{c}\text { Diameter of indentation } \\
(\mathbf{m m})\end{array}$ & Hardness (BHN) \\
\hline Pure Aluminium & 1.63 & 59 \\
\hline Al-Si-Alloy & 1.63 & 96 \\
\hline Al-SiC-Gr Composite & 1.58 & 108 \\
\hline
\end{tabular}


The hardness of aluminium alloy (LM-25), aluminium alloy reinforced with $10 \% \mathrm{SiC}$ andaluminium alloy reinforced with $10 \% \mathrm{SiC} \& 5 \%$ Graphite were checked and compared. The hardness of the composites were checked by micro Vickers hardness tester with $0.5 \mathrm{Kg}$ load applied [8]

Table 5: Hardness of composites [8]

\begin{tabular}{|c|l|c|c|c|c|}
\hline S.No & \multicolumn{1}{|c|}{ Material } & $\begin{array}{c}\text { Position 1 } \\
\text { (HBN) }\end{array}$ & $\begin{array}{c}\text { Position 2 } \\
(\text { HBN })\end{array}$ & $\begin{array}{c}\text { Position 3 } \\
(\mathbf{H B N})\end{array}$ & $\begin{array}{c}\text { Average } \\
(\mathbf{H B N})\end{array}$ \\
\hline 1 & Aluminium alloy (LM-25) & 67.4 & 69.1 & 72.0 & 69.5 \\
\hline 2 & $\mathrm{Al}+10 \% \mathrm{SiC}$ & 90.3 & 90.2 & 93.8 & 91.4 \\
\hline 3 & $\mathrm{Al}+10 \% \mathrm{SiC}+5 \% \mathrm{Gr}$ & 87.0 & 87.7 & 81.6 & 85.4 \\
\hline
\end{tabular}

The hardness of $\mathrm{SiC}$ reinforced composite is higher compared to fiber reinforced composite [14]. The less frictional heat generation in the tool manufactured from aluminium composite will result in less hardness value [15]. The hardness of aluminium alloy increases with addition of $9 \mathrm{wt} \%$ of fiber reinforcement [16]. The softening of aluminium alloy results in decreased micro hardness value [17]. The $25 \%$ weight fraction of 320 grit size of SiC particles shows micro hardness value of 45.5 BHN [18]. Micro hardness of AL7075 improved by $35 \%$ by heat treatment [19]. The addition of fly ash content increases the hardness strength [22].The hardness increases with increasing wt.\% of Gr reinforcement and it further increased by adding $1 \mathrm{wt} . \%$ of $\mathrm{Mg}$ in $\mathrm{Gr}$ [23].

The hardness of the EN coated alloy is greater than that of uncoated aluminium alloy. Further, it is observed that the $20 \mu \mathrm{m}$ coated alloy exhibits higher hardness compared to that of $10 \mu \mathrm{m}$ coated alloy. It clearly shows that Hardness increases with the increasing thickness of the EN coating [24].

The hardness value increases as the weight fraction of $\mathrm{SiC}$ and Fly Ash reinforcements increases. This is due to the fact that hard $\mathrm{SiC}$ particles contribute more positively to the hardness of the hybrid composites. The increase in hardness is due to the hard SiC particles which act as a barrier for the movement of dislocation within the base matrix [25].The hardness and strength of the composites increased with the addition of reinforcement like $\mathrm{SiC}, \mathrm{Al} 2 \mathrm{O} 3, \mathrm{TiB} 2, \mathrm{~B} 4 \mathrm{C}, \mathrm{TiC}$ etc. $\mathrm{B} 4 \mathrm{C}$ provides more hardness and strength as compared to others [26]. The hardness of the area influenced by the thermal, both retreating and advancing with increased hardness for all experimental conditions compared to that of base metal. But for the stir zone, the hardness can either be increased or decreased. The condition that increases the hardness is travelling speed at 120 and $160 \mathrm{~mm} / \mathrm{min}$ with any rotation speed. The condition that reduces the hardness is travel speed at $80 \mathrm{~mm} / \mathrm{min}$ with any rotation speed. The highest hardness is obtained at $1750 \mathrm{rpm}$ with travel speed at 160 $\mathrm{mm} / \mathrm{min}$, is equal to $64.55 \mathrm{HV}$, an increase of $59.07 \%$ compared to the base metal [27].The addition of $\mathrm{TiB} 2$ with aluminium matrix increases the hardness value. It has been also noted that when \%of TiB2 increases up to 5\% there is a sudden decrease in hardness value. This decrease in the hardness value is due to cluster formation which leads to porosity [28].

A load of $500 \mathrm{kgf}$ is applied for 30 seconds on AMC-FA and AMC-AV and the average diameter of the indentation left in respective specimens are $4.18 \mathrm{~mm}$ and $3.91 \mathrm{~mm}$ respectively. The Brinell hardness number (BHN) is calculated by dividing the load applied by the surface area of the indentation. The BHN values obtained for AMC-FA and AMC-AV are 28.2 and 33.8 respectively [29]. 


\subsection{Studies on Compression Test}

Figure 4 shows the compression strength of Al-TiN composite specimens. The findings indicate a significant increase in compression strength with the addition of TiN reinforcement into aluminium. This is due to the reinforcing effect on aluminium. Uniform distribution of particles has resulted in improved compression strength. The compression strength of 15 wt.\% TiN reinforced aluminium composite was found to be $37 \%$ higher than that of unreinforced aluminium [5].

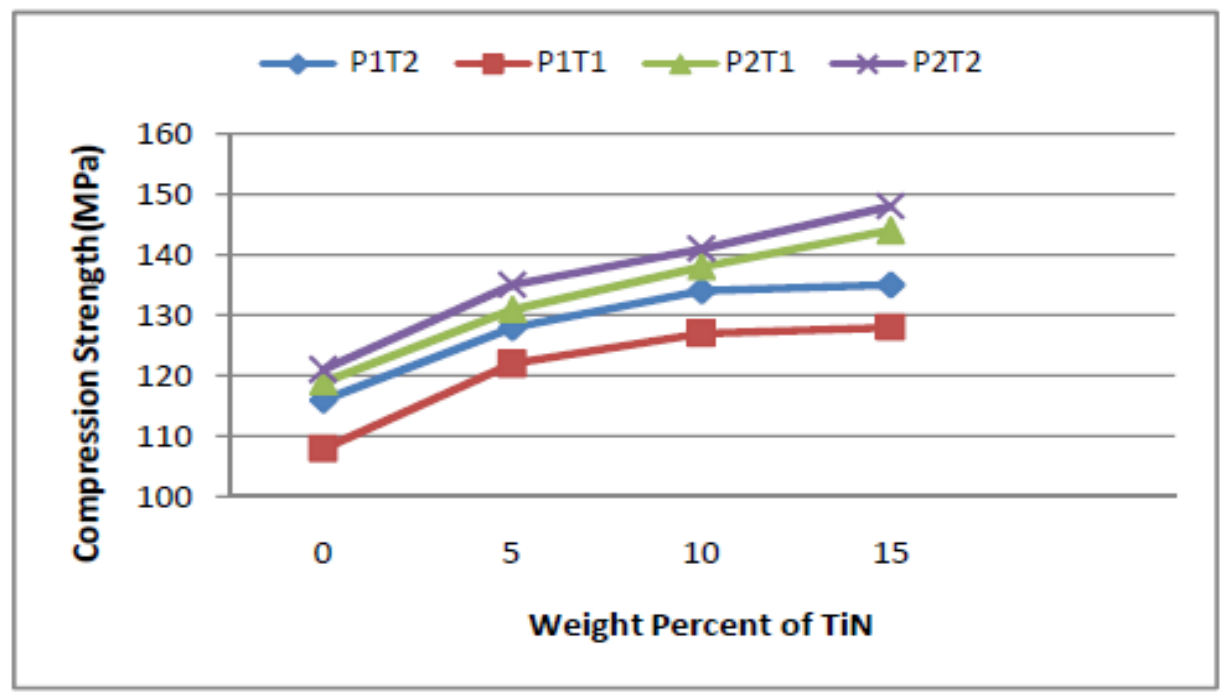

Figure 4: Variation of Compressive strength for different weight percentages of TiN reinforced $\mathrm{Al}$ composites at various compacting pressure and sintering temperature [3]

Test has been conducted till failure point thus ultimate load of $104 \mathrm{KN}$ against the failure for Al-GBF was found to be more when compared with Al-FLY ASH, with a load of $89 \mathrm{KN}$ and AL-2024, with a load of $75 \mathrm{KN}$. Upon conduction of compression test load versus displacement graphs have been resulted such graphs have been depicted in the figures 5,6 and 7 [6]. The addition of graphite and fly ash with Aluminium alloy of LM 25 as the base metal with varying percentage of silicon carbide $(2 \%, 4 \%$ and $6 \%)$ displayed the best combination that can withstand the compressive force [13].

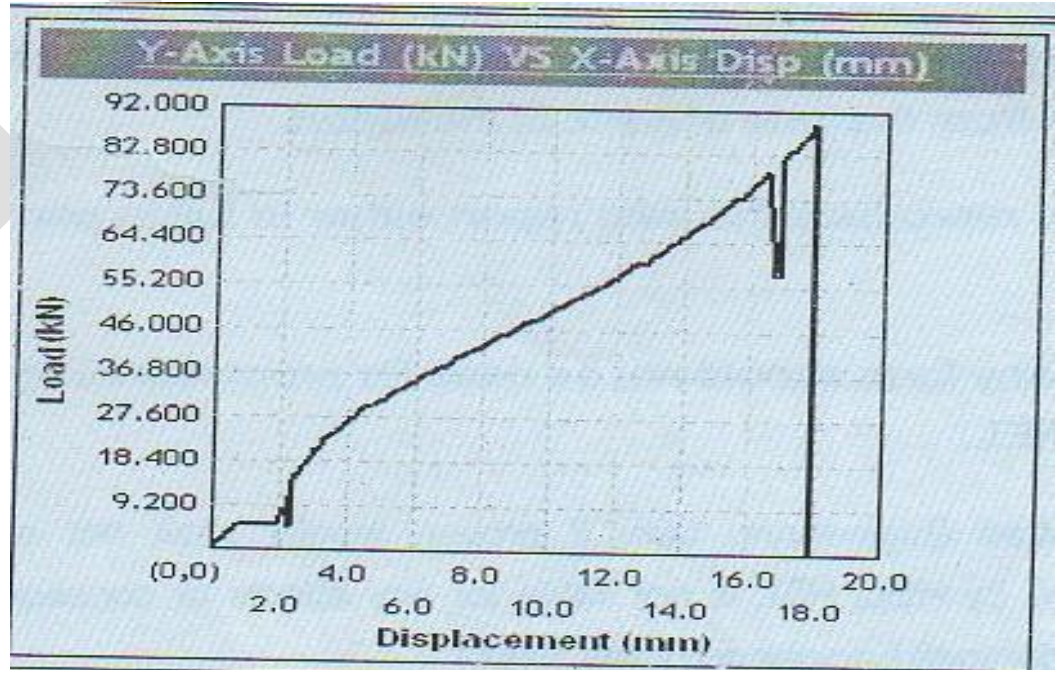

Figure 5: Test report of compression test of Al-Fly ash [6] 


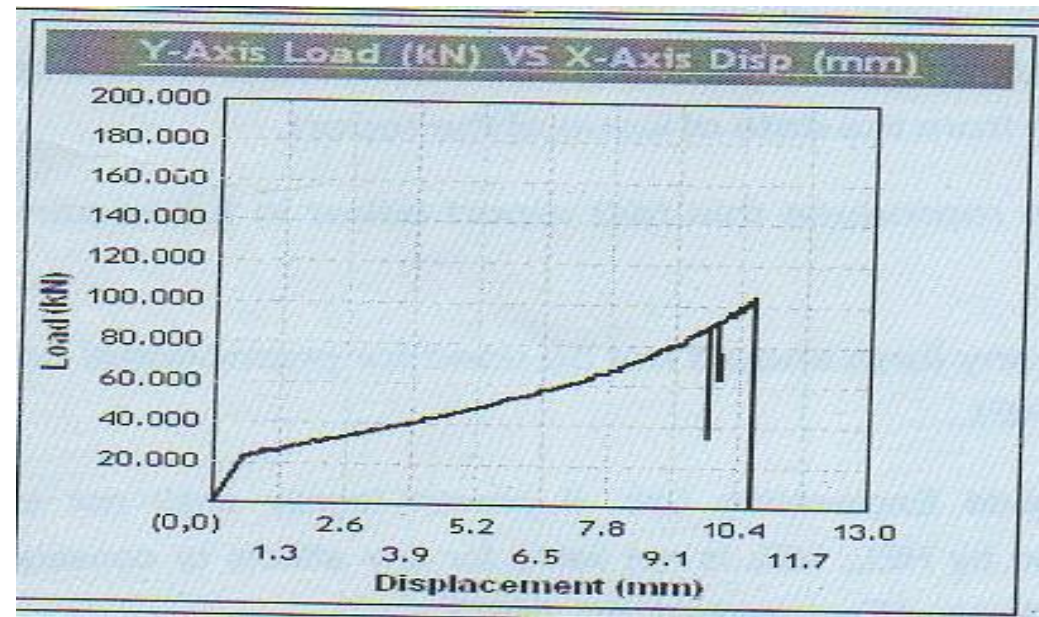

Figure 6: Test report of compression test of Al-GBF [6]

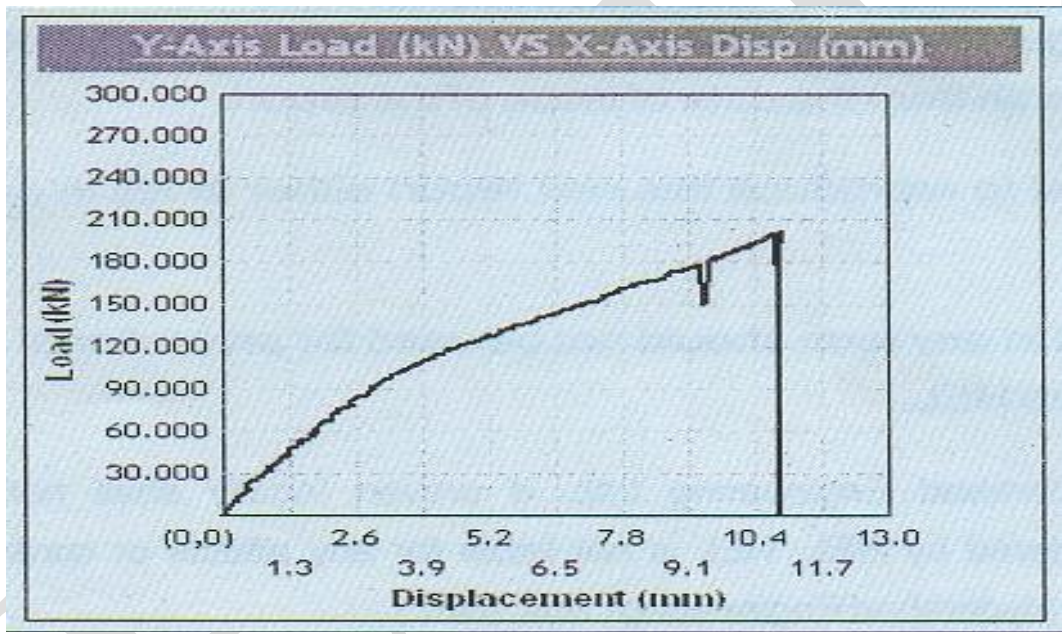

Figure 7: Test report of compression test of Al 2024 [6]

\subsection{Studies on Wear Test}

Wear test was conducted for base alloy and SiC graphite composite reinforced with two different particle sizes of 63 and 37 microns. Graphite was added as fine powder whereas $\mathrm{SiC}$ was added as particles. The wear test was conducted for different loads from 1 to $4 \mathrm{~kg}$ by keeping sliding distance of $2 \mathrm{~km}$ as constant. The observed results of mass loss for varying particle size of graphite with various loading conditions for two different particle sizes of 63 and 37 microns with base alloy. Similarly for different particle size of graphite the wear rate with various loads were analyzed. It was clearly found that the mass loss increases with increase in load during the analysis of prepared composite materials, also it was found that the base alloy shows appreciable mass loss when compared with the SiC-Gr reinforced composites [7].

The same trend was observed for the wear rate also. As the load increases the wear rate also increases and base alloy shows the maximum wear. When the load was $4 \mathrm{~kg}$, the effect of graphite was considerable which paved the way for reduction in mass loss and wear rate [7]. The wear behavior of the $\mathrm{Al}-\mathrm{SiC}$ is investigated at room conditions at four different loads, $70 \mathrm{~N}, 80 \mathrm{~N}, 90 \mathrm{~N}, 100 \mathrm{~N}$ and with varying sliding speeds like 200, 300, 400, 500, 600, $700 \mathrm{rpm}$, using a pin-on-disk wear testing machine [9]. At higher loads, onset Delamination of sub surfaces for both aluminium matrix alloys and silicon carbide based aluminium MMCs 
also responsible for higher wear rates which results in increased amount of the plastic deformation and cracking of surface which results in higher material removal from surfaces [10].

An increase in sliding velocity considerably affects the wear rate. The wear rate decreases sharply with increase in sliding velocity for composites with relatively higher weight fraction. However, even with increasing sliding velocity, the un-reinforced alloy showed higher wear rate compared to composites [11].The wear volume and wear factors both have decreased as the percentage of hematite increased [12].The wear decreases with increase in volume content of reinforcements [20].The wear resistance of the fabricated composites increases with the increase in the fly ash contents. The composites with high fly ash contents resulted in $13.6 \%$ less wear as compared to low fly ash content composites [21]. The wear of test material attained at constant applied weight, the composite material shows signs of a lower wear failure compared with strengthened Al alloy [30].

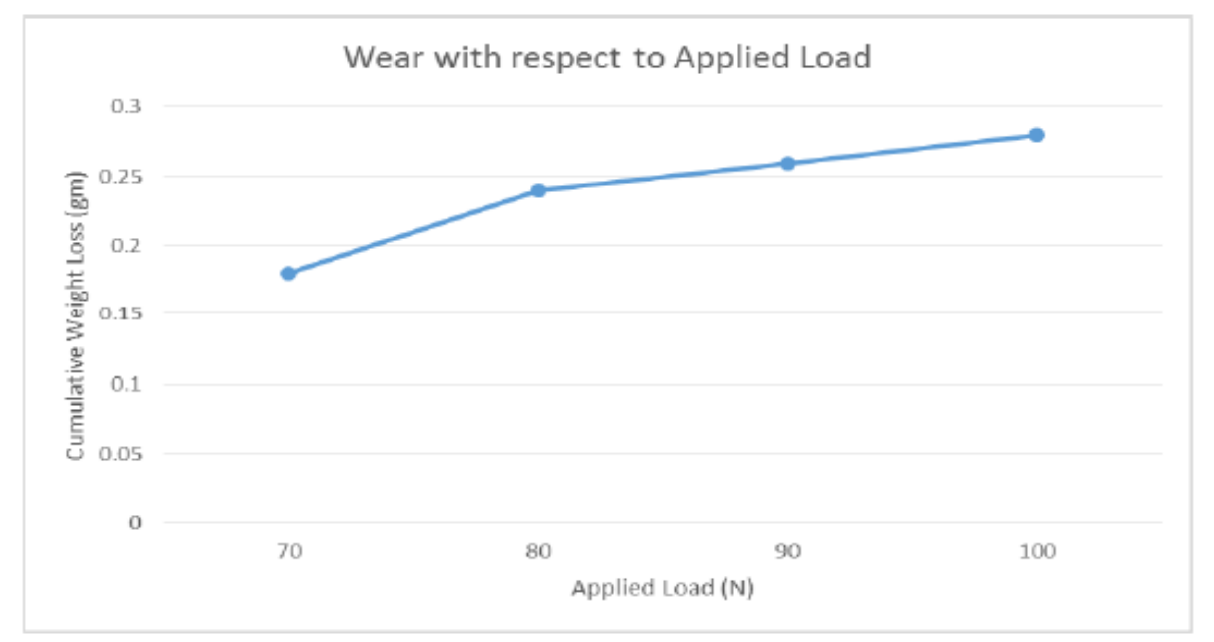

Figure 8: Graph - cumulative weight loss vs applied load [9]

\section{CONCLUSION}

The study on the mechanical properties and wear behaviour of aluminium metal matrix composites with different reinforcement materials showed that:

- The hardness value of TiC reinforced aluminium is higher when compared to pure aluminium. The addition of $\mathrm{SiC}$ to $\mathrm{TiC}$ reinforced composite shows increase in micro hardness value.

- The addition of $\mathrm{SiC}$ and $\mathrm{TiC}$ makes the ductile aluminium alloy into more brittle in nature.

- The surface roughness of the composites developed decreased with increase in the amount of reinforcement, compacting pressure and sintering temperature.

- The hardness value of Al-Fly ash composite varies from one point to another point because of factors like variation in composition and type of cooling.T he impact strength of Al-Fly ash is greater than the Aluminium-Granulated blast furnace slag.

- The uniform distribution of TiN particles results in 37\% higher compression strength than unreinforced aluminium.

- In aluminium silicon and graphite powder composite, the hardness was better than the base alloy. It was also reported that an increase in tensile strength and reduction in mass loss and wear rate was found during mechanical and wear tests. At higher loads, the wear rate of composites increases. 


\section{REFERENCES}

[1] P.K. Sinha, "Composite materials and structures", composite centre of excellence, AR\&DB, Department of aerospace engineering, IIT Kharagpur, 2006

[2] Azom, Composite Matrix Materials, https://www.azom.com/article.aspx?ArticleID=9814

[3] S. Pradeep Devaneyan, R. Ganesh, and T. Senthilvelan, "The Mechanical Properties of Hybrid Aluminium 7075 Matrix Composite Material Reinforced with SiC and TiC Produced by Powder Metallurgy Method", Indian journal of material science, pp. 1-6, 2017

[4] Ragul Manoharan, Revanth Shankar, Richard Joseph, Hariharasakthisudan," Characterization of mechanical properties of aluminium composites fabricated by stir-casting and powder metallurgy", International Journal of Mechanical Engineering and Technology (IJMET),volume 8, issue 6, pp. 176-189, 2017

[5] L Mahesh, J Sudheer Reddy, P G Mukunda, "Studies on titanium nitride reinforced aluminium metal matrix composites", International Journal of Mechanical Engineering and Technology (IJMET), volume 8, issue 3, pp. 114-122, 2017

[6] J. Manoj Kumar, N Gopikrishna, "Comparative studies on mechanical characteristics of granulated blast furnace slag and fly ash reinforced aluminium composites", International Journal of Mechanical Engineering and Technology (IJMET), Volume 8, Issue 11, pp. 277284, 2017

[7] A. Karthikeyan, S. Nallusamy, "Investigation on Mechanical Properties and Wear Behaviour of Al-Si-SiC-Graphite Composite using SEM and EDAX”, IOP Conference Series: Materials Science and Engineering, 2017

[8] R. Meenakshisundaram, V. Kalaiyarasan, P. Vijayakumar, "Experimental study on the mechanical properties of hybrid aluminium metal matrix composite and optimization of machining parameter in milling”, International Journal of Mechanical Engineering and Technology (IJMET), Volume 8, Issue 3, pp. 319-330, 2017

[9] Vicky Kumar, Jitendra Kumar, Sunil Kumar, Sandeep, "Study on wear behavior of aluminium metal matrix composite reinforced with SiC", International Research Journal of Engineering and Technology (IRJET), Volume 3, Issue 5, 2016

[10] Kalyan Kumar Singh, Saurabh Singh, Anil Kumar Shrivastava, "Comparison of wear and friction behaviour of aluminium matrix alloy and silicon based aluminium metal matrix composite under dry condition at different sliding distance", International Conference on Advancements in Aeromechanical Materials for Manufacturing (ICAAMM), pp. 89608971,2016

[11] V. Ramakoteswaran Rao, N. Ramnaiah, M. Sarcar, " Tribological properties of aluminium metal matrix composites (AA7075 reinforced with titanium carbide particles", International Journal of Advanced Science and Technology (IJAST), Volume 88, pp. 13-26, 2016

[12] M.V. Phanibhushana, C.N. Chandrappa, H.B. Niranjan, "Study of wear characteristics of hematite reinforced aluminium metal matrix composites", International Conference of Material Processing and Characterization (ICMPC), pp. 3484-3494, 2016

[13] Rohit Sharma, SaurabhJha P, KhushbooKakkar, Kushal Kamboj, PardeepSharma, " $A$ Review of the Aluminium Metal Matrix Composite and its Properties", International Research Journal of Engineering and Technology (IRJET), Volume 04, pp. 382-393, 2017

[14] S. Rajesh, B. VijayaRamnath, C. Elanchezhian, N. Aravind, V. Vijai Rahul, S. Sathish. "Analysis of Mechanical Behavior of Glass Fiber/ Al2O3- SiCReinforced Polymer composites", Global Congress on Manufacturing and Management (GCMM), pp. 398-407, 2014

[15]Inderjeet Singh, Gurmeet Singh Cheema, Amardeep Singh Kang, “An experimental approach to study the effect of welding parameters on similar friction stir welded joints of 
AZ31B-O Mg alloy”, Global Congress on Manufacturing and Management (GCMM), pp. 837-847, 2014

[16] Madhukumar, Umashankar, "Characterization of Glass Particulate Reinforced Aluminium Alloy6061 Metal Matrix Composites”, International Conference on Emerging Trends in Materials and Manufacturing Engineering (IMME), pp. 7604-7609, 2018

[17] R. Dhayalan, K. Kalaiselvan, R. Sathiskumar, "Characterization of AA6063/SiC-Gr Surface Composites Produced by FSP Technique", Global Congress on Manufacturing and Management (GCMM), pp. 625-632, 2014

[18] ManojSingla, D. Deepak Dwivedi, Lakhvir Singh, Vikas Chawla, "Development of Aluminium based Silicon Particulate Metal Matrix Composite", Journal of Minerals and Material Characterization and Engineering (JMMCE), Volume 8, pp. 455-467, 2009

[19] T. S. A. Suryakumai, S. Ranganathan, J. Sai Krishna, N. Sanjeev Sai Reddy, K. Loknath Reddy, "Development of Aluminium Hybrid Metal Matrix Composite", Asian Research Publishing Network (ARPN), Volume 11, pp. 7973-7978, 2016

[20] K. Umanath, S. T. Selvamani, K. Palanikumar, R. Sabarikreeshwaran, "Dry Sliding Wear Behaviour of AA6061-T6 Reinforced SiC and Al2O3 Particulate Hybrid Composites" Global Congress on Manufacturing and Management (GCMM), pp. 694-703, 2014

[21] Vipin K. Sharma, R.C. Singh, Rajiv Chaudhary, "Effect of fly ash particles with aluminium melt on the wear of aluminium metal matrix composites", Engineering Science and Technology, pp. 1318-1323, 2017

[22] Prakash Rao C.R., Bhagyashekar M.S, Narendraviswanath, "Effect of Machining Parameters on the Surface Roughness while Turning Particulate Composites", Global Congress on Manufacturing and Management (GCMM), pp. 421-431, 2014

[23] Poonam Sundriyal, P. L. Sah, "Enhancement of Mechanical Properties of Graphite Particulate Aluminum Metal Matrix Composites by Magnesium Addition”, International Conference on Recent Trends in Engineering and MaterialSciences (ICEMS), pp. 9481-9487, 2016

[24] Mohan Kumar S, Pramod R, Shashi Kumar M E, Govindaraju H K, "Evaluation of Fracture Toughness and Mechanical Properties of Aluminum Alloy 7075, T6 with Nickel Coating”, Global Congress on Manufacturing and Management (GCMM), pp. 178-185, 2014

[25] B. Ramgopal Reddy, C. Srinivas, "Fabrication and Characterization of Silicon Carbide and Fly Ash Reinforced Aluminium Metal Matrix Hybrid Composites", International Conference on Emerging Trends in Materials andManufacturing Engineering (IMME), pp. 8374-8382, 2017

[26] Yashpal, Sumankant, C.S.Jawalkar, Ajay Singh Verma, N.M.Suri, "Fabrication of Aluminium Metal Matrix Composites with Particulate Reinforcement: A Review", International Conference of Materials Processing and Characterization (ICMPC), pp. 29272937, 2016

[27] S. Chainarong a*, P. Muangjunburee b, S. Suthummanon, "Friction Stir Processing of SSM356 Aluminium Alloy”, Global Congress on Manufacturing and Management (GCMM), pp. 732-741, 2014

[28] JohnyJames.S, Venkatesan.K, Kuppan.P, Ramanujam.R, "Hybrid Aluminium Metal Matrix Composite Reinforced with SiC and TiB2",Global Congress on Manufacturing and Management (GCMM), pp. 1018-1027, 2014

[29] C.HimaGireesh, K.G.Durga Prasad, K.Ramji, P.V.Vinay, "Mechanical Characterization of Aluminium Metal Matrix Composite Reinforced with Aloe vera powder", International Conference of Materials Processing and Characterization (ICMPC), pp. 3289-3298, 2017 [30] K.Umanatha, S.T.Selvamani, K.Palanikumar,D.Niranjanavarma, "Metal to Metal Worn Surface of AA6061 Hybrid Composites Casted by Stir Casting Method”, Global Congress on Manufacturing and Management (GCMM), pp. 703-713, 2014 